\title{
Diagnosis and management of anorectal gonorrhoea in women*
}

\author{
VALERIE A STANSFIELD \\ From the Middlesex Hospital Medical School, London
}

SUMMARY A retrospective assessment of 159 female patients who had undergone proctoscopy was carried out between January and September 1977. One hundred and twenty-seven (80\%) were known contacts of gonorrhoea; of these, $63(49 \cdot 6 \%)$ were found to be infected with Neisseria gonorrhoeae. Of these, $29(46 \%)$ harboured gonococci in the rectum as well as in the urethra and cervix while four $(6 \cdot 3 \%)$ harboured gonococci only in the rectum. Gram-stained smears gave positive results in only 12 of the 29 cases of rectal gonorrhoea, which indicates the importance of culturing rectal material. It is recommended that the management of anorectal gonorrhoea should be similar to that already established for urogenital infection.

\section{Introduction}

Anorectal gonorrhoea in women is an important and probably underdiagnosed disease. It rarely causes any symptoms or signs and is best detected by proctoscopy and microscopical examination and confirmed by culture. Studies during the last 10 years have shown anorectal infection in $40-63.7 \%$ of women diagnosed as having gonorrhoea. Parisier ${ }^{1}$ reported that $40 \%$ of women with gonorrhoea had positive rectal culture results. Olsen ${ }^{2}$ found positive results in rectal investigations in $63.7 \%$ of a group of 265 women who were contacts of men with gonorrhoea; in 3\%, the rectal site alone gave a positive result.

Rectal investigations are not routine procedure in many clinics. Adler ${ }^{3}$ found that they were carried out on female contacts of gonorrhoea by physicians in only $20 \%$ of clinics. It is important to know which patients are at risk from anorectal gonorrhoea and consequently where resources should be directed. In these patients with anorectal gonorrhoea, adequate follow up should be undertaken.

At James Pringle House, the Middlesex Hospital, London, proctoscopy is performed on female contacts of men treated for gonorrhoea, usually at the first visit; if omitted for any reason, it is undertaken at the next visit, particularly when urethral and cervical investigations give negative

* Paper submitted for the MSSVD Student Prize, 1979

Address for reprints: Dr V A Stansfield, 45 Brookdale Road, London E17 6QL

Received for publication 4 August 1979 results. Patients with anorectal symptoms, or a history of anal intercourse, are also offered rectal examination. This study is a retrospective assessment by means of case records of all female patients in whom rectal investigations had been carried out during the period January to September 1977.

\section{Patients and methods}

The patients were all seen at James Pringle House, the Middlesex Hospital, London. A history was taken, including details and dates of recent sexual intercourse, contraception, and antibiotic treatment. Rectal examination was carried out with a metal proctoscope, which was introduced using a small amount of lubricating jelly. Urethral, cervical, and rectal specimens were taken with wire loops; the samples were stained by Gram's method and examined under the microscope. Specimens for culture were inoculated directly on to culture plates of a blood agar medium containing vancomycin $(3 \mu \mathrm{g} / \mathrm{ml})$ and colistin $(8 \mu \mathrm{g} / \mathrm{ml})$. The plates were put into a candle extinction jar in the clinic incubator. The full jars were transferred to the laboratory and incubated for 24 hours in candle extinction jars and then for a further 24 hours in the laboratory incubator. Plates were examined after 48 hours' incubation. Oxidase testing was carried out and oxidase-positive colonies were stained by Gram's method. Gram-negative cocci were subcultured for penicillin sensitivity and sugar fermentation tests.

\section{Results}

Proctoscopy was performed in 159 women. Of these, 
$127(80 \%)$ were contacts of confirmed cases of gonorrhoea, and $63(49 \cdot 6 \%)$ had gonococci at one or more of three sites (table I). Of these, rectal infection was found in $29(46 \%)$ and infection of the rectum alone in four $(6 \cdot 3 \%)$ (table II).

TABLE I History and symptoms of female patients having contact with confirmed cases of gonorrhoea

\begin{tabular}{lc}
\hline Symptoms/history & No of female patients \\
\hline Anorectal & 2 \\
Vaginal and abdominal & 12 \\
Anal intercourse & 5 \\
Gonococci at one or more sites & 63 \\
Total & 127 \\
\hline
\end{tabular}

TABLE II Sites of gonococcal infection in 63 female patients

\begin{tabular}{lcc}
\hline Site & No & $\%$ \\
\hline Urethra alone & 2 & $3 \cdot 2$ \\
Cervix alone & 13 & $20 \cdot 6$ \\
Urethra + cervix & 19 & $30 \cdot 2$ \\
Total & 34 & 54 \\
Urethra + cervix + rectum & 14 & $22 \cdot 2$ \\
Urethra + rectum & 2 & $3 \cdot 2$ \\
Cervix + rectum & 9 & $14 \cdot 3$ \\
Rectum alone & 4 & $6 \cdot 3$ \\
Total & 29 & 46 \\
\hline
\end{tabular}

\section{MICROSCOPY AND CULTURE}

The results of rectal investigations and the visit at which diagnosis was made are shown in table III. Seventeen $(58 \cdot 6 \%)$ cultures gave positive results for Neisseria gonorrhoeae, although the results of the Gram-stained smears were negative. In 10 cases $(34 \cdot 5 \%)$, the results of both Gram-stained smears and cultures were positive, and in two $(7 \%)$ the results of the smears were positive but those of the cultures were negative. In the latter two patients, one culture was overgrown with Proteus species and the other showed no growth, although the smear was confirmed as showing typical intracellular diplococci. Culture was essential for diagnosis; in over half the confirmed cases of gonorrhoea the results of the smears were negative. In three of the four patients with gonorrhoea affecting only the

TABLE III Results of rectal investigations

\begin{tabular}{llllll}
\hline Results & & & \multicolumn{2}{c}{ Proctoscopy } & \\
\cline { 5 - 6 } Smear & Culture & & At lst visit & At 2nd visit & Total \\
\hline+ & - & 1 & 1 & 2 \\
+ & + & 8 & 2 & 10 \\
- & 10 & 7 & 17 \\
Total & + & 19 & 10 & 29 \\
\hline
\end{tabular}

+ Positive - negative rectum, diagnosis was made by culture after proctoscopy at the second visit. In each of these patients only urethral and cervical investigations had been carried out during the first visit. In the other patient with anorectal gonorrhoea alone, positive rectal results were obtained at the first visit.

\section{OTHER INFECTIONS}

Various other conditions were found during routine investigations (table IV). Trichomoniasis was the most common concurrent vaginal infection, being found in $17 \cdot 2 \%$ of the patients with rectal gonorrhoea.

TABLE IV Other conditions diagnosed

\begin{tabular}{lll}
\hline & \multicolumn{2}{l}{ No of women } \\
\cline { 2 - 3 } Condition & $\begin{array}{l}\text { With gonorrhoea } \\
\text { (all cases) }\end{array}$ & $\begin{array}{l}\text { With anorectal } \\
\text { gonorrhoea }\end{array}$ \\
\hline Trichomoniasis & $11(17 \cdot 5 \%)$ & $5(17 \cdot 2 \%)$ \\
Candidosis & 3 & 1 \\
Syphilis & 1 & \\
Herpes genitalis & 1 & \\
\hline
\end{tabular}

\section{TREATMENT}

The drugs used in the treatment of patients with gonorrhoea are given in table V. One patient was treated elsewhere, one defaulted before treatment could be given for a positive culture result, and six patients defaulted from follow up. The treatment was successful in all the remaining cases as confirmed by two sets of smears and cultures with negative results.

\section{TABLE V Drugs used in the treatment of gonorrhoea}

\begin{tabular}{lll}
\hline Drug & Dosage & No of cases \\
\hline Benzylpenicillin & $\begin{array}{l}5 \text { megaunits i m } \\
\text { preceded by } 1 \mathrm{~g} \text { oral } \\
\text { probenecid }\end{array}$ & 52 \\
$\begin{array}{l}2 \text { tablets twice daily } \\
\text { for } 4 \text { days }\end{array}$ & 7 \\
Co-trimoxazole & $\mathrm{g} \mathrm{m}$ & 2 \\
\hline
\end{tabular}

NO HISTORY OF CONTACT WITH GONORRHOEA

The remaining 32 patients had no history of contact with gonorrhoea. Of these, 23 had anorectal symptoms or admitted to anal intercourse (table VI). The remaining nine requested examination to exclude sexually transmitted disease. Anorectal disease was diagnosed in two cases, both of these being anal infections due to Candida albicans.

\section{Discussion}

The overall incidence of positive results for gonorrhoea from rectal specimens in this series $(\mathbf{4 6 \%})$ 
TABLE VI Symptoms of patients with no history of contact with gonorrhoea

\begin{tabular}{ll}
\hline Symptoms & No of patients \\
\hline Anorectal alone & 11 \\
Anorectal + anal intercourse & 6 \\
Anal intercourse alone & 6 \\
No anorectal + no anal intercourse & 9 \\
Anal candidosis & 2 \\
\hline
\end{tabular}

compares with that of Bhattacharyya and Jephcott ${ }^{4}$ $(45 \%)$ and that of Schmale and others ${ }^{5}(50 \%)$.

Culture is shown to be essential in the diagnosis of rectal gonorrhoea in conjunction with microscopical examination of Gram-stained smears. Twenty-seven of the 29 specimens gave positive results by culture but only 12 by Gram-stain alone. This is probably due to the difficulty in staining and reading rectal smears.

Four patients harboured gonococci only in the rectum. If proctoscopy had not been carried out in these cases, the patients would have been considered free of infection. Only two of the 29 patients with rectal gonorrhoea had rectal symptoms and in only four proctoscopic examinations was any mucopus seen in the rectum. The patients' symptoms were anal irritation and pain on defecation.

The overall incidence of trichomoniasis $(17 \cdot 5 \%)$ and the similar incidence $(\mathbf{1 7 \cdot 2 \% )}$ in patients with gonorrhoea affecting the rectum compare with an overall incidence of $19 \%$ found by Erikkson and Wanger ${ }^{6}$ in their study on infections concurrent with gonorrhoea. How infection reaches the rectum in these patients who deny anorectal contact is still uncertain, but it seems reasonable that patients with the profuse watery vaginal discharge associated with trichomonal infection are at greater risk of urogenital gonorrhoea spreading to the rectum, as suggested by King. ${ }^{7}$

In this clinic, patients with urogenital gonorrhoea are discharged after treatment, if the results of two sets of smears and cultures are negative; the same procedure is followed when anorectal gonorrhoea is diagnosed. However, if rectal investigations are not carried out before treatment is given, no diagnosis of rectal gonorrhoea can be made and it is therefore impossible to make an informed decision on how many follow-up investigations are required.

This study shows that anorectal gonorrhoea is an important aspect of the disease and is present in a growing number of cases. Investigations after treatment are considered to be an essential part of the management of urogenital gonorrhoea. Anorectal gonorrhoea should be managed similarly; the disease may be excluded after two proctoscopic examinations and a cure considered when two negative results have been obtained. It is recommended that diagnostic proctoscopy be carried out in all women with gonorrhoea and in those who are contacts of patients with gonorrhoea. Management should then be the same as that for urogenital disease.

I thank the staff of James Pringle House, especially Dr R D Catterall and Professor M W Adler for their help and encouragement.

\section{References}

1. Parisier H. Asymptomatic gonorrhoea. Med Clin North Am 1972; 56:1127-32.

2. Olsen GA. Value of vaginal and rectal cultures in the diagnosis of gonorrhoea. With special reference to areas with limited medical facilities. Br J Vener Dis 1971;47: 102-6.

3. Adler MW. Diagnostic, treatment and reporting criteria for gonorrhoea in sexually transmitted disease clinics in England and Wales. 1 Diagnosis. Br J Vener Dis 1978;54:10-4.

4. Bhattacharyya MN, Jephcott AE. Diagnosis of gonorrhoea in women. Role of the rectal sample. $B r J$ Vener Dis 1974;50: 109-12.

5. Schmale JD, Martin JE, Domescik G. Observations on the culture diagnosis of gonorrhoea in women. JAMA 1969;210:312-7.

6. Eriksson G, Wanger L. Frequency of $N$ gonorrhoeae, $T$ vaginalis and $C$ albicans in female venereological patients. A one-year study. Br J Vener Dis 1975;51: 192-7.

7. King AJ. The complications of homosexuality. Introduction. Proc $R$ Soc Med 1962;55: 869-70. 